American Journal of Agricultural and Biological Sciences 4 (4): 283-288, 2009

ISSN 1557-4989

(C) 2009 Science Publications

\title{
Assessment on the Effect of Formulative Materials on the Viability and Efficacy of Serratia marcescens-a Biocontrol Agent Against Fusarium oxysporum F. sp. cubense race 4
}

\author{
A.S.Y. Ting, M.T. Fang and C.S. Tee \\ Department of Science, Faculty of Engineering and Science, \\ University Tunku Abdul Rahman, Kuala Lumpur, Malaysia
}

\begin{abstract}
Problem statement: Application of biocontrol agents to the field in pre-existing free-cell forms often results in poor cell viability which subsequently affects their efficacy in suppressing pathogen development. There is therefore a need to bioformulate these biocontrol agents not just to enhance their field potential, but for easy storage, delivery and application as well. Approach: In this study, the bioformulations for a biocontrol bacterium Serratia marcescens, was developed using bentonite clay as carrier material with various combinations of enrichment and additive materials. The most suitable bioformulation was determined by assessing the compatibility of the formulative materials in preserving cell viability during storage, the resulting appearance of the bioformulation, the protection confered to cells upon sunlight exposure and the efficacy of the formulated cells (with and without sunlight exposure) in inhibiting the growth of the pathogenic Fusarium oxysporum F. sp. cubense race 4 (FocR4). Results: Bioformulation benefited the cells when exposed to sunlight (UV rays). The benefits of bioformulation were attributed to the carrier material (bentonite clay) and the enhancement materials (NFSM and sucrose). They confer UV-protectant effects as well as providing nutrient source for the formulated cells. The additive material PABA was observed to have antimicrobial effect on the formulated cells. Formulative materials however has no impact on the efficacy of the cells in inhibiting FocR4 as no significant differences in percentages of FocR4 inhibition were observed between bioformulations with and without exposure to sunlight. Conclusion: Present study observed that incorporation of sucrose into Bentonite (BS) has the most potential for large-scale testing as it showed good viability and efficacy results.
\end{abstract}

Key words: Bentonite, bioformulations, non-fat skimmed milk, sucrose, sunlight exposure

\section{INTRODUCTION}

The application of many biocontrol agents at the glasshouse and field stage is often hampered by the susceptibility of the viable cells to the unfavorable environmental conditions. As a result, many biocontrol agents only showed impressive control efficacy in suppressing the growth of the pathogen at the laboratory stage, or at best, the glasshouse stage ${ }^{[6]}$. One of the main reasons for the failure of biocontrol agents to exhibit efficient control is their poor viability in the soil, resulting from soils which are too acidic under water-logged conditions ${ }^{[10]}$, or due to the intense competition with the indigenous microflora in the soil to establish their own niche and existence in the soil environment. Therefore, to ensure that the biocontrol agents remain viable when introduced into the soil, they must be protected from these unfavorable conditions which may diminish their viability and subsequently affect their efficacy towards the pathogens.

One such approach to ensure the viability of cells is to formulate the viable cells using suitable formulative materials ${ }^{[4]}$. Formulative materials consist of the carrier, enrichment, additive and the active materials (viable cells), each integrating with one another so that the active cells derive benefits from this combination of mixtures ${ }^{[14]}$. Since most bioformulation of beneficial isolates are meant for field application, it is essential that the formulative materials used are able to maintain cell viability under adverse environmental conditions, so that they can persist longer in the soil to inhibit resting structures like sclerotia and chlamydospores of the pathogen which are more difficult to eliminate or control $^{[8]}$.

Corresponding Author: A.S.Y. Ting, Department of Science, Faculty of Engineering and Science,

University Tunku Abdul Rahman, Jalan Genting Kelang, Setapak 53300, Kuala Lumpur, Malaysia Tel: 603-41079802 Fax: 603-41079803 
In present study, we examined the potential of combining several formulative materials to protect the cells of Serratia marcescens, a bacterium which have showed immense potential in managing Fusarium wilt disease of bananas caused by the fungal pathogen Fusarium oxysporum F. $\mathrm{sp}$. cubense race 4 (FocR4) ${ }^{[15,17]}$. We selected bentonite, a type of montmorillonite clay as the carrier material; non-fat skimmed milk (NFSM) and sucrose as enrichment materials; and Para-Aminobenzoic Acid (PABA) as a UV protectant agent. The carrier materials and enrichment materials are aimed to protect the active cells from temperature changes and desiccation ${ }^{[18,19]}$, while PABA has a protective role against intense UV rays from the sunlight ${ }^{[19]}$. Their combination is expected to permit the retention of cell viability ${ }^{[4]}$ thus increasing the effectiveness of the active material ${ }^{[18]}$. We therefore tested these formulative materials in various combinations and their impact on cell viability in bioformulations exposed to and without exposure to sunlight (UV rays) was determined. In addition, formulated cells of $S$. marcescens were also tested for their efficacy in reducing the inoculum of FocR4 in a laboratory-scale testing and the results reported in this paper.

\section{MATERIALS AND METHODS}

Isolate preparation: The isolate $S$. marcescens was previously isolated from roots of wild bananas and have shown ability to promote growth of banana plantlets ${ }^{[16]}$ and demonstrated initial Fusarium wilt suppression effect in a field trial ${ }^{[17]}$. This isolate was cultured on Luria Bertani (LB) Agar (Pronadisa) and incubated for $48 \mathrm{~h}$ at room temperature $\left(27 \pm 2^{\circ} \mathrm{C}\right)$ prior to use. Stock cultures were maintained on LB agar slants. The fungal pathogen Fusarium oxysporum F. sp. cubense race 4 (FocR4) was obtained from Prof Dr. Sariah Meon from University Putra Malaysia as filter-paper cultures. The fungal cultures were re-established on Potato Dextrose Agar (Merck) and incubated for $48 \mathrm{~h}$ at room temperature $\left(27 \pm 2^{\circ} \mathrm{C}\right)$ prior to use.

Bioformulation of viable cells of $S$. marcescens: Seven combinations of the bioformulation were prepared, each comprising of $180 \mathrm{~g}$ of bentonite clay and inoculated with $180 \mathrm{~mL}$ of inoculum suspension. The inoculum suspension was achieved by dislodging bacterial cells from LB agar plates using LB broth and adjusted with $\mathrm{LB}$ broth to $15 \log _{10} \mathrm{CFU} \mathrm{mL}^{-1}$ (absorbance value of 1.60 at $540 \mathrm{~nm}$ ). For bioformulation containing only bentonite clay (B), no other formulative materials were incorporated except the inoculum. For bioformulations using bentonite clay and a combination of enrichment materials such as NFSM (BN) and sucrose (BS), $15 \mathrm{~g}$ each of NFSM and sucrose was incorporated, respectively. PABA was added at a rate of $1.5 \mathrm{~g}$ for every $180 \mathrm{~g}$ of bentonite clay, into separately prepared Bentonite (BP), Bentonite with NFSM (BNP) and Bentonite with Sucrose (BSP). A bioformulation mixture containing all enrichment and additive materials tested (BNSP) was also prepared using similar compositions. The dough-like bentonitebased bioformulations were moulded under aseptic conditions to form coarse granules that were then evenly spread-out and distributed on several sterile disposable petri dishes for oven-drying (Memmert) $\left(30 \pm 2^{\circ} \mathrm{C}\right)$. After 3 days of drying, the granules were grind and sieved through a $1.0 \mathrm{~mm}$ testing sieve (ColeParmer, WW-59980-05, 16 mesh). The resulting finer granules, now measuring approximately $0.5-1.0 \mathrm{~mm}$ in granule size, were then stored in $1000 \mathrm{~mL}$ glass Schott bottles at room temperature $\left(27 \pm 2^{\circ} \mathrm{C}\right)$ for subsequent experiments. In addition to the seven combination of bioformulations, two controls were also prepared that were Free-Cell suspension (FC) and bacterial cell-free Bentonite Clay (BC). Free-cell bioformulation was prepared using $180 \mathrm{~mL}$ of inoculum suspension $\left(15 \log _{10} \mathrm{CFU} \mathrm{mL}^{-1}\right.$ ). The $\mathrm{BC}$ bioformulation was achieved by mixing $180 \mathrm{~g}$ bentonite clay with $180 \mathrm{~mL}$ of sterile deionised water. BC formulation was also dried and grind as for previous formulations. Both control treatments prepared were also stored in $1000 \mathrm{~mL}$ glass Schott bottles at room temperature $\left(27 \pm 2^{\circ} \mathrm{C}\right)$ for subsequent experiments.

Viability assessment: The viability of formulated $S$. marcescens was assessed and compared to the viability of non-formulated cells (control, FC) to determine the effect of formulative materials on cell viability. Viability assessment was conducted at every monthly interval throughout the 6 months storage period. During each assessment, $1.0 \mathrm{~g}$ of the bioformulation was sampled and suspended in $15 \mathrm{~mL}$ of sterile deionised water. A serial dilution was then performed until $10^{4}$ dilution times. From each diluted sample, $0.02 \mathrm{~mL}$ aliquot was pipetted and spread onto LB agar plates. The plates were then incubated at room temperature $\left(27 \pm 2^{\circ} \mathrm{C}\right)$ for 2 days. Colonies formed on the LB agar plates were then enumerated. The procedure was repeated for all bentonite-based bioformulations. For free-cell suspension, the same procedure was repeated, substituting the bioformulations with $0.50 \mathrm{~mL}$ of freecell suspension. The procedure was also conducted for all bioformulations exposed to $6 \mathrm{~h}$ of sunlight (UV rays) for viable cell enumeration. 
Efficacy assessment: The efficacy of formulated cells of $S$. marcescens in inhibiting the growth of the pathogenic FocR4 was determined by assessing the number of FocR4 colonies recovered upon exposure to the formulated bacterial cells, as compared to exposure to Free-Cell forms (FC) of $S$. marcescens. This in vitro assessment was initiated by mixing $1.0 \mathrm{~g}$ of the bioformulation (or $0.5 \mathrm{~mL}$ of free-cell suspension) with $20.0 \mathrm{~mL}$ of sterile deionised water in a $50 \mathrm{~mL}$ test tube. After mixing well, $1.0 \mathrm{~mL}$ of FocR 4 suspension (6.5 $\log _{10} \mathrm{CFU} \mathrm{mL} \mathrm{m}^{-1}$, absorbance value of 0.980 at $600 \mathrm{~nm}$ ) was then inoculated into the mixture. A control was also prepared by inoculating $1.0 \mathrm{~mL}$ of FocR 4 into $20.0 \mathrm{~mL}$ of sterile deionised water. The tubes were then incubated at room temperature $\left(27 \pm 2^{\circ} \mathrm{C}\right)$ for 7 days. The number of FocR4 colonies recovered from treatment with each bioformulation was enumerated using similar procedure as in viability assessment, substituting LB agar with PDA supplemented with $1 \mathrm{~g} \mathrm{~L}^{-1}$ streptomycin (amResco®) for plating purposes selective for FocR4. The percentage of inhibition of FocR4 was calculated as:

$$
[(\mathrm{X}-\mathrm{Y}) / \mathrm{X}] \times 100
$$

Where:

$\mathrm{X}=$ The CFU mL $\mathrm{mL}^{-1}$ of FocR4 in the control tube $\mathrm{Y}=\mathrm{The} \mathrm{CFU} \mathrm{mL} \mathrm{m}^{-1}$ of FocR4 treated with formulated cells

The procedure was also repeated for all bioformulations exposed to $6 \mathrm{~h}$ of sunlight to determine the efficacy of formulated cells in inhibiting FocR4 after sunlight exposure.

Experimental design and statistical analysis: The experiments were conducted in a complete randomized design, with duplicates for each viability and efficacy assessments. Results obtained were analyzed with the SAS program (Statistical Analysis System). The mean comparison for bioformulations exposed and nonexposed to sunlight was compared with Tukey's Studentized Range Test $\left(\mathrm{HSD}_{0.05}\right)$. The comparison of the effect of sunlight exposure within a single bioformulation was compared with $\mathrm{T}$-test ( $\mathrm{p} \geq 0.05)$.

\section{RESULTS}

Viability assessment: Active cells of $S$. marcescens responded differently to the influence of mixtures of formulative materials and their subsequent exposure to UV treatment. Contrary to our hypothesis that bioformulation increases viability of cells, our results indicated that Free-Cell suspension (FC) was the most suitable for storage of cells after a 6-month period with a mean viable cell count of $5.7 \log _{10} \mathrm{CFU} \mathrm{mL} \mathrm{mL}^{-1}$ (Fig. 1). Formulated cells (B, BN, BP, BS, BNP, BSP and $\mathrm{BNSP}$ ) on the other hand, produced lower viable cell counts than FC after storage for 6 months at room temperature. Nevertheless, their lower number of viable cell count was not significantly different from FC (Fig. 1). Among the bentonite bioformulations, combinations with enrichment materials (NFSM, sucrose) were more beneficial than the additive material (PABA) as observed from BN and BS, compared to BP bioformulations, respectively (Fig. 1). Presence of NFSM and sucrose in $\mathrm{BN}$ and $\mathrm{BS}$ bioformulations produced relatively higher viable cell count and were able to sustain cell viability even in bioformulations with PABA (BNP, BSP, BNSP), thus eliminating the negative influence of PABA (BP) (Fig. 1). The benefits of formulative materials in sustaining cell viability were clearly observed when the formulated cells were exposed to sunlight (UV rays). The mean viable cell counts for all bentonite-based bioformulations (except BP) were slightly higher than FC suspension (Fig. 1). Bentonite bioformulations incorporated with NFSM and sucrose (BN, BS, BNP, BSP, BNSP), were again observed to sustain cell viability better than bentonite bioformulation with the addition of PABA (BP). Comparisons between the viable cell count after sunlight exposure within the same bioformulation type revealed that five of the eight bioformulations-B, BP, $\mathrm{BS}, \mathrm{BNP}$ and BSP bioformulations, were able to protect the cells as the viable cell count after and before sunlight exposure were not significantly different (Table 1). Only FC, BN and BNSP bioformulations recorded statistically different values (Table 1), indicating a significant reduction in the number of viable cells recovered after sunlight exposure compared to no sunlight exposure.

Table 1: T-test comparison to evaluate the significant difference in viable cell count of $S$. marcescens recovered from bioformulations exposed to sunlight and without sunlight exposure

\begin{tabular}{lll}
\hline T-test & t-value & Pr $>|t|$ \\
\hline FC & 4.09 & $0.0094^{*}$ \\
B & 1.20 & 0.2845 \\
BN & 2.71 & $0.0421^{*}$ \\
BP & 0.10 & 0.9278 \\
BS & 2.46 & 0.0575 \\
BNP & 1.85 & 0.1242 \\
BSP & 2.02 & 0.0992 \\
BNSP & 2.87 & $0.0349^{*}$ \\
\hline
\end{tabular}

*: Statistically different $(\mathrm{p} \leq 0.05)$; Note: $\mathrm{FC}$ : free-cell suspension, $\mathrm{B}$ : bentonite clay, N: non-fat skim milk, S: Sucrose; P: PABA 


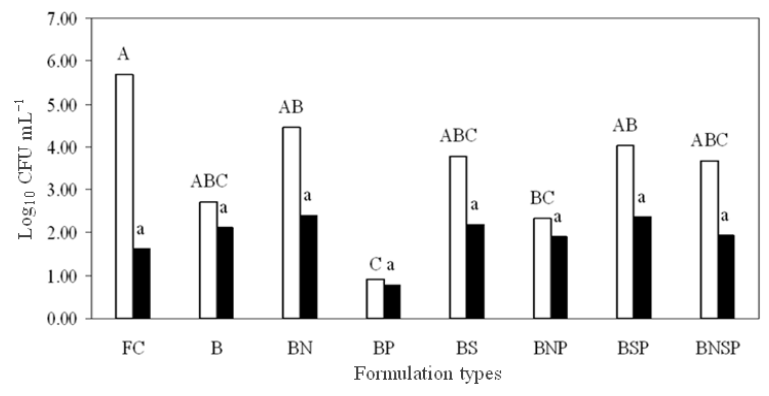

Fig. 1: Mean viable cell count $\left(\log _{10} \mathrm{CFU} \mathrm{mL}^{-1}\right)$ for isolate $S$. marcescens in various bioformulations compared to control (FC). Open barsbioformulations and FC without sunlight exposure; shaded bars-bioformulations and FC with sunlight exposure. Means with the same letters and same captions are not significantly different $\left(\mathrm{HSD}_{(0.05)}\right)$. (Note: FC: Free-Cell suspension; B: Bentonite clay; N: Non-fat skim milk; S: Sucrose; P: PABA)

Efficacy assessment: Formulated cells of $S$. marcescens recorded varying percentages of inhibition towards FocR4 with higher percentages recorded by bioformulations without exposure to sunlight (Fig. 2). Cells formulated with the additive material PABA (BP) showed highest efficacy in inhibiting the growth of FocR4 followed by BNSP and FC, with 13.38, 8.71 and $8.45 \%$, respectively (Fig. 2). Bentonite bioformulations with enrichment materials (NFSM, sucrose) were less effective in inhibiting the growth of FocR4. In fact, more viable cells of FocR4 were recovered from BNP bioformulation, suggesting no inhibition occurred but growth stimulation (Fig. 2). The poor inhibition towards FocR4 by some bioformulations was more evident after exposure to sunlight for $6 \mathrm{~h}$. Five bioformulations-B, $\mathrm{BN}, \mathrm{BNP}, \mathrm{BSP}$ and BNSP, recorded increased growth instead of reduction in viable cell count of FocR4. These bioformulations resulted in a $5-10 \%$ increase in viable cell count of FocR4 (Fig. 2). Therefore, among the formulated forms of $S$. marcescens, only the bioformulations BC, BP, BS and FC, were able to inhibit FocR4 after exposure to sunlight (Fig. 2). Comparisons within the same bioformulation type discovered that all bioformulations were able to produce similar percentages of inhibition, regardless of the exposure to sunlight (Table 2). This suggested that the incorporation of PABA, did not significantly improve efficacy of formulated cells upon exposure to sunlight. The presence of NFSM and sucrose were also not particularly beneficial to aid in FocR4 inhibition as their presence in bioformulations BN, BS, BNP, BSP and BNSP, did not result in significant differences (Table 2).

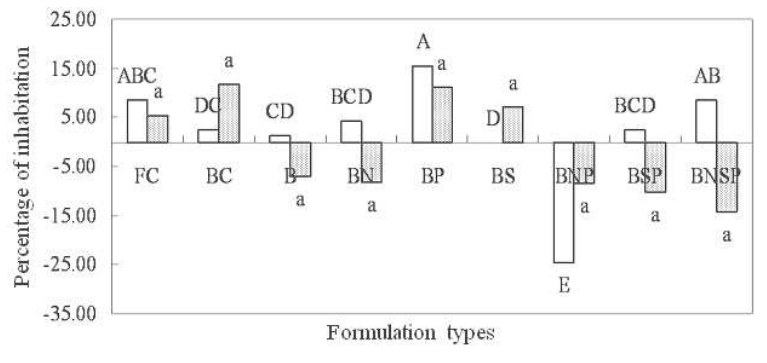

Fig. 2: Percentage of FocR4 inhibition by isolate $S$. marcescens in various bioformulations compared to control (FC). Open barsbioformulations and $\mathrm{FC}$ without sunlight exposure; shaded bars-bioformulations and FC with sunlight exposure. Means with the same letters and same captions are not significantly different $\left(\operatorname{HSD}_{(0.05)}\right)$. (Note: $\mathrm{FC}$ : Free-Cell suspension; BC: Bacterial Cell-free bentonite clay; B: Bentonite clay, N: Non-fat skim milk; S: Sucrose; P: PABA)

Table 2: T-test comparison to evaluate the significant difference in percentage of inhibition towards FocR4 by $S$. marcescens cells from bioformulations exposed to sunlight and without sunlight exposure

\begin{tabular}{lcc}
\hline T-test & t-value & $\operatorname{Pr}>|t|$ \\
\hline FC & 0.51 & 0.7005 \\
BC & -0.76 & 0.5868 \\
B & 1.76 & 0.3282 \\
BN & 3.12 & 0.1976 \\
BP & 1.83 & 0.3181 \\
BS & -0.08 & 0.9496 \\
BNP & -0.98 & 0.5079 \\
BSP & 2.32 & 0.2588 \\
BNSP & 8.91 & 0.0712 \\
\hline
\end{tabular}

Note: FC: Free-Cell suspension, B: Bentonite clay, N: Non-fat skim milk, S: Sucrose; P: PABA

\section{DISCUSSION}

Results from our study suggested that the formulative materials were not particularly beneficial when used to bioformulate cells of $S$. marcescens for storage purposes, but rendered more benefits to the viable cells when they are meant for field application that is with the exposure to sunlight. This was evident when the Free-Cell suspension (FC) which produced the highest viable cell count after 6 months of storage, had significantly reduced viable cell count upon exposure to sunlight. This was mainly attributed to the absence of the bentonite-clay, NFSM, sucrose and PABA, which individually or collectively, act as UV radiation screens thus protecting the viable cells ${ }^{[2]}$. Bentonite-clay is known for their UV, temperature and desiccation protectant effects ${ }^{[18,19]}$. As a result, higher 
cell viability is recovered from bentonite-based bioformulations compared to Free-Cell suspension (FC) after exposure to sunlight as cells entrapped in this clay-based carrier material were able to withstand exposure to sunlight. In addition, bentonite clay is a type of montmorillonite clay with the ability to absorb large quantities of water resulting in an increase in volume and cation exchange capacity which leads to higher cell viability ${ }^{[1,3]}$. Therefore, we presumed that when the inoculum suspension was introduced into the bentonite clay, most of the viable cells in the suspension were efficiently absorbed, the bacterial metabolic activity enhanced and protected from UV, resulting in the higher cell viabilities recovered from bentonite-based formulations compared to FC after sunlight exposure. Contrary, the strong sorption affinity of the cells to the bentonite-clay may have resulted in the poor release of cells when resuspended in sterile distilled water during the enumeration exercise. This probably explains the slightly lower recovery rate of viable cells from bentonite-based bioformulations compared to FC after storage at room temperature.

The addition of NFSM and sucrose into bioformulations developed in this study also contributed to the increase in the viability of $S$. marcescens, for both conditions with and without sunlight exposure. Cell viability was maintained as NFSM and sucrose provided necessary nutrients especially carbon source to support cell growth ${ }^{[9]}$. In conditions when the bioformulations were exposed to sunlight, NFSM function as a suitable rehydration medium for the formulated cells upon contact with water ${ }^{[5]}$. Sucrose on the other hand, conveyed UV protectant effect by acting as the osmoprotectant agent and preventing severe desiccation of cells upon sunlight exposure ${ }^{[5,7]}$. Our results also report that the incorporation of PABA into the bioformulations did not yield the expected results of better cell viability after sunlight exposure. Although PABA is a compound known for its UV protectant ability and is used in many applications such as in sunscreen products ${ }^{[11]}$, their incorporation into bioformulations in this study was detrimental. Our results, where very low recovery of viable cells was observed especially in BP, suggested potential antimicrobial activity towards $S$. marcescens, highlighting the antimicrobial nature of PABA compared to other organic acids ${ }^{[13]}$.

Although the formulative materials were advantages in protecting the formulated cells from sunlight exposure, their role in enhancing the control efficacy towards FocR4 was less defined. There were no clear improvements on the inhibitory effect towards FocR4 upon the introduction of the formulated cells compared to FC in both conditions with or without sunlight exposure. Therefore, we conclude that the higher viability of cells derived from bioformulations upon sunlight exposure may not necessarily have an advantage in producing better control efficacy. Our results in the efficacy assessment also indicated that the incorporation of NFSM and sucrose into bioformulations (BN, BS, BNP, BSP and BNSP), resulted in the increase of FocR4 viable cells instead of an inhibition. This clearly showed that NFSM and sucrose rendered benefits to both $S$. marcescens and FocR4. Similarly, PABA also exhibited antimicrobial effect to both isolates. This highlighted the importance of careful evaluation of the use of enhancement and additive materials as part of the bioformulation as they do not discern between rendering benefits to either beneficial isolate or to the pathogen.

\section{CONCLUSION}

To conclude, our study showed that formulative materials used in the bioformulation of $S$. marcescens have a significant impact in improving cell viability compared to FC after sunlight exposure. This confirms the objective of bioformulating active cells of beneficial isolates for various applications in the field ${ }^{[12]}$ as in formulated forms; a certain number of viable cell inoculum is retained for control expression despite the unfavorable environmental conditions. Our bioformulations here indicated that bentonite-based bioformulation with sucrose (BS) can produce both good viability and efficacy results, even after exposure to sunlight. PABA was determined as an unsuitable additive material despite its UV protectant claims and is recommended for omission from future bioformulation studies. We highly recommend the bioformulation of $S$. marcescens for both storage and field purposes considering their eventual application to the field.

\section{ACKNOWLEDGEMENT}

The researchers extend their gratitude to the Malaysian Ministry of Science, Technology and Innovation for the research grant awarded. Also to Prof Dr. Sariah Meon who has availed the use of the FocR4 culture in this study.

\section{REFERENCES}

1. Adamis Z., R.B. Williams and J. Fodor, 2005. Bentonite, kaolin and selected clay minerals. International Programme on Chemical Safety (IPCS)-World Health Organization (WHO), Switzerland. http://www.inchem.org/documents/ehc/ehc/ehc231. htm 
2. Behle, R.W., M.R. McGuire, R.L. Gillespie and B.S. Shasha, 1997. Effects of alkaline gluten on the insecticidal activity of Bacillus thuringiensis. J. Econ. Entomol., 90: 354-360. http://www.bioone.org/loi/ecen

3. Beveridge, T.J. 1988. The bacterial surface: General considerations toward design and function. Can. J. Microbiol., 34: 363-372. DOI: 10.1139/m88-067

4. Brar, S.K., M. Verma, R.D. Tyagi and J.R. Valero, 2006. Recent advances in downstream processing and formulations of Bacillus thuringiensis based biopesticides. Process Biochem., 41: 323-342. DOI: 10.1016/j.procbio.2005.07.015

5. Costa, E., J. Usall, N. Teixido, N. Garcia and I. Vinas, 2000. Effect of protective agents, rehydration media and initial cell concentration on viability of Pantoea agglomerans strain CPA-2 subjected to freeze-drying. Applied Microbiol., 89: 793-800. DOI: $10.1111 / \mathrm{j} .1365-2672.2005 .02587$

6. Elliot, L.F. and J.M. Lynch, 1995. The international workshop on the establishment of microbial inocula in soils. Cooperative research project on biological resource management of the Organisation for Economic Cooperation and Development (OECD). Am. J. Alternat. Agric., 10: $50-73$.

http://library.wur.nl/WebQuery/artik/lang/875085

7. Gouffi, K. and C. Blanco, 2000. Is the accumulation of osmoprotectant the unique mechanism involved in bacterial osmoprotection?. Int. J. Food Microbiol., 55: 171-174. http://www.ncbi.nlm.nih.gov/pubmed/10791739

8. Irshad, L., S. Dawar and M.J. Zaki, 2006. Effect of different dosages of nursery fertilizers in the control of root rot of Okra and Mung bean. Pak. J. Bot., 38: 217-223. http://www.pakbs.org/pjbot/PDFs/38(1)/PJB38(1)2 17.pdf

9. Lee, S.Y. and H.N. Chang, 2004. High cell density cultivation of Escherichia coli W using sucrose as a carbon source. Biotechnol. Lett., 15: 971-974. DOI: $10.1007 / \mathrm{BF} 00131766$

10. Lynch, J.M., 1995. Microbial Activity in Acid Soils. In: Plant-Soil Interactions at Low $\mathrm{pH}$ : Principles and Management, Date, R.A., N.J. Grundon, Rayment, G.E. and M.E. Probert (Eds.). Kluwer Academic Publishers, Dordrecht, The Netherlands, ISBN: 0792331982, pp: 167-172.

11. Miao, L.H., K.C. Yang, C.C. Ling and M. Sano, 1995. Para-aminobenzoic acid scavenges reactive oxygen species and protects DNA against UV and free radical damage. J. Nutr. Biochem., 6: 504-508. DOI: 10.1016/0955-2863(95)00082-B
12. Ragaei, M. 1999. Radiation protection of microbial pesticides. Applied Entomol., 123:381-384. DOI: 10.1046/j.1439-0418.1999.00363

13. Richards, R.M.E., D.K.L. Xing and T.P. King, 1994. Activity of p-aminobenzoic acid compared with other organic acids against selected bacteria. Applied Microbiol., 78: 209-215. DOI: 10.1111/j.1365-2672.1995.tb05018

14. Schisler, D.A., P.J. Slininger, R.W. Behle and M.A. Jackson, 2004. Symposium the nature and application of biocontrol microbes: Bacillus spp. formulation of Bacillus spp. for biological control of plant diseases. National Center for Agricultural Utilization Research (NCAUR), US J. Am. Phys. Soc., 94: 1267-1271. http://apsjournals.apsnet.org/doi/pdf/10.1094/PHY TO.2004.94.11.1267? cookieSet=1

15. Ting, A.S.Y., M. Sariah, K. Jugah, S. Radu and S. Gurmit, 2004. Diversity of endophytes from wild bananas and their potential as bioagents against Fusarium wilt. Proceedings of the Plant Health Conference: Role of Crop Protection in Enhancing the 3rd Engine of Growth, Apr. 21-22, Bangi, Selangor, Malaysia, pp: 55-57.

16. Ting, A.S.Y., M. Sariah, J. Kadir, S. Radu and S. Gurmit, 2008. Endophytic microorganisms as potential growth promoters of banana. BioControl, 53: 541-553. DOI: 10.1007/s10526-007-9093-1

17. Ting, A.S.Y., M. Sariah, J. Kadir and S. Gurmit, 2009. Field evaluation of non-pathogenic Fusarium oxysporum isolates UPM31P1 and UPM39B3 for the control of Fusarium wilt in 'pisang Berangan' (MUSA, AAA)'. Acta Hortic. (ISHS), 828: 139-144. http://www.actahort.org/members/showpdf?booknr arnr $=828 \_13$

18. Tu, M. and J.M. Randall, 2005. Adjuvants. In: Weed Control Methods Handbook: Tools and Techniques for Use in Natural Areas, Tu, M., C. Hurd and J.M. Randall (Eds.). The Nature Conservancy's Global Invasive Species Team, USA., pp: 8.1-8.225.

19. Vettori, C., E. Gallori and G. Stotzky, 2000. Clay minerals protect bacteriophage PBS1 of Bacillus subtilis against inactivation and loss of transducing ability by UV radiation. Can. J. Microbiol., 46: 770-773. DOI: 10.1139/cjm-46-8770 